\title{
CATEGORIAS MARXISTAS E ANÁLISE DO PROCESSO DE VALORAÇÃO E FINANCEIRZAÇÃO CAPITALISTA DA NATUREZA
}

\author{
CATEGORÍAS MARXISTAS Y ANÁLISIS DEL PROCESO DE VALORACIÓN Y \\ FINANCIACIÓN CAPITALISTA DE LA NATURALEZA
}

\section{MARXIST CATEGORIES AND ANALYSIS OF NATURE'S CAPITALIST FINANCIALIZATION AND VALUATION PROCESS}

DOI: http://dx.doi.org/10.9771/gmed.v13i2.45048

\author{
Ana Consuelo Ferreira Fontenele ${ }^{1}$
}

Alexandrina Luz Conceição ${ }^{2}$

\begin{abstract}
Resumo: O artigo faz considerações acerca da crise ambiental contemporânea, a partir das categorias, natureza com valor de uso, valor de troca e financeirizada, como explicação da relação sociedade-natureza no ciclo do capital. $O$ objetivo é expor a exploração capitalista da natureza como determinações sociais que historicamente produzem as condições limítrofes à vida. O artigo está organizado em duas seções: a primeira trata da condição de realização de separação entre a sociedade e a natureza; apropriação, mercantilização e inscrição nos circuitos de exploração do capital. A segunda seção analisa a forma financeirizada de circulação do capital inscrito no processo de valorização das economias verdes.
\end{abstract}

Palavras-chave: Crise ambiental. Relação sociedade-natureza. Economia verde.

Resumen: El artículo hace consideraciones sobre la crisis ambiental contemporánea, desde las categorías, naturaleza con valor de uso, valor de cambio y financiarizada, como explicación de la relación sociedad-naturaleza en el ciclo del capital. El objetivo es exponer la explotación capitalista de la naturaleza como determinaciones sociales que históricamente producen las condiciones limítrofes de la vida. El artículo se organiza en dos apartados: el primero trata sobre la condición de separación entre sociedad y naturaleza: apropiación, comercialización y registro en los circuitos de exploración de capitales. La segunda sección analiza la forma de circulación financiarizada del capital que se registra en el proceso de valoración de las economías verdes.

Palabras clave: Crisis ambiental. Relación sociedad-naturaleza. Economía verde.

Abstract: This article makes considerations about the environmental crisis based on the categories "nature with use value", "exchange value" and "financialized nature " as an explanation of the society-nature relationship in the capital cycle. The main objective of the article is to expose the capitalist exploitation of nature as social determinations that historically produce precarious life conditions. The article is organized in two sections: the first section deals with the condition of separation between society and nature, more specifically, the appropriation, commercialization and registration in the capital exploration circuits. The second section analyzes the financialized form of circulation of capital registered in the process of valuing green economies.

Keywords: Environmental crises. Society-nature relationship. Green economy

\section{Introdução}

A crise estrutural do capital tem exposto a violência do seu caráter destrutivo nas suas práticas de expropriação do trabalho e da natureza na busca crescente pelo lucro, que esbarra no limite absoluto da 
existência humana. A perspectiva iminente dos riscos da destruição da natureza e o consequente fim da humanidade tornam inquestionáveis os argumentos filosóficos analíticos do pensamento marxiano da relação metabólica homem-natureza, que substantiva o entendimento do movimento contraditório dos limites absolutos do capital e de possíveis mediações na reconstituição da esfera política, no controle e planejamento capaz de superar a crise estrutural.

$\mathrm{Na}$ busca de encontrar definições, o contexto emerge a introdução do debate a partir do questionamento: existe um marxismo ecológico?

John Bellamy Foster, ao publicar o livro A Ecologia de Marx: Materialismo e Natureza no ano 2005, sustenta que o pensamento marxiano é integralmente ecológico, estando teoricamente fundamentado nos estudos da relação sociedade-natureza, sendo o método do materialismo histórico-dialético indissociável da preocupação "ecológica". Foster afirma que seu entendimento do marxismo ecológico teve como direção o livro de Paul Burkett, que fundamentou suas reflexões na defesa do pensamento marxista como base substantiva para a explicativa da crise ambiental ${ }^{3}$ contemporânea. No seu livro Marx and Nature. A red and green perspective, Burkett (1999), defende que Karl Marx, a partir do método do materialismo histórico, explica as interrelações entre a natureza e a evolução da sociedade.

Assim como Foster (2005) e Burkett (1999), Elmar Altvater (2006), compreende que "O conceito marxista de relação natureza-homem é muito mais apropriado que outros conceitos para compreender as contradições e a dinâmica da relação social entre o ser humano e natureza, [...] entre a economia, a sociedade e o meio ambiente" (ALTVATER, 2006, p. 346).

O conceito de dialética da natureza para Marx é um processo de troca material mediada pelo trabalho4. Processo através do qual o homem transforma a realidade natural, intitulada de "primeira natureza" e produz sobre uma "segunda natureza" (humanizada). A prática humana é parte do metabolismo homem-natureza, os seres humanos dependem da natureza, a sua vida depende do saber usá-la de forma adequada para viver. Toda produção é apropriação da natureza; a produção é imediatamente consumo e duplo consumo (subjetivo e objetivo). A produção é composta por atos de consumo, cada um imediatamente seu contrário. Um consumo sem objeto não é consumo, portanto, a produção cria, origina consumo, mas não gera somente o objeto de consumo (MARX, 2013). Conforme leitura diferenciada dos economistas clássicos, Karl Marx afirma que a relação do produto com o produtor não se limita a uma relação dupla, mas esta se dá exteriormente na sociedade e depende das relações entre os indivíduos, através das leis sociais, imediatamente subsumidas no processo de distribuição, em múltiplas determinações que tem como determinalidade a relação capital-trabalho. Há uma interação entre produção, distribuição, troca e consumo entre os diferentes momentos, sendo que cada qual se constitui em si uma particularidade, mas todos fazem parte de uma totalidade.

O processo de produção do capital se diferencia de outras formas materiais de produção por trocar uma parte de seu ser objetivo por trabalho.

[...] o processo de trabalho - que, em virtude de sua abstratividade, de sua pura materialidade, é comum a todas as formas de produção - posto antes do valor, como ponto de 
partida, reaparece no interior do capital como um processo que se desenrola no interior de sua matéria, que constitui seu conteúdo (MARX, 2011, p. 237).

"O trabalho só é produtivo na medida que produz seu próprio contrário" (MARX, 2011, p. 238). Como valor de uso, ele só existe para o capital porque produz valor de troca. O trabalho que é vendido pelo trabalhador ao capital como valor de uso, como condição de troca ele é determinado como valor de qualquer outra mercadoria. Destaca-se que, no sistema do capital, a natureza é transformada em mercadoria, deixando de ter valor de uso e passando a condição de valor de troca; a sua condição é gerar lucro, não para o bem-estar da sociedade humana mas para a privatização. Não há conciliação histórica possível entre uma produção voltada para o lucro - cuja dinâmica inexorável é a da acumulação do capital, onde perpassa a utilização irracional e ambientalmente incorreta dos recursos naturais. O sistema sociometabólico do capital induz a expansão capitalista para garantir a ampliação da produção de valores de troca.

O capitalismo é um sistema expansionista onde tudo é interpretado como matéria-prima para o processo de produção de valor e mais valor. "Se não é útil, como não pode satisfazer necessidade, a matéria-prima será considerada inútil, sem valor e, portanto, um objeto inadequado a valorização capitalista" (ALTVATER, 2006, p. 343).

Logo, a crise de acumulação capitalista deve ser entendida como uma crise ecológica. Segundo Elmar Altvater (2006, p. 343), “ao separar os recursos que possuem valor daqueles que são inúteis, a integridade da natureza será indevidamente desintegrada e a desintegração da natureza é sua destruição”. A crise do capitalismo e a crise ecológica resultam da dinâmica do sistema capitalista, que transforma seres humanos e recursos naturais em mercadorias necessárias à expansão dos negócios e a acumulação de lucros.

Ao refletir sobre a crise estrutural do Capital, István Mészáros (2011), alerta sobre os limites absolutos da existência humana. Na leitura do Capital, Karl Marx afirma que o verdadeiro limite da produção capitalista é o próprio capital. São o capital e a sua própria valorização que constituem o ponto de partida e a meta, o motivo e o fim da produção. Seus limites, para garantir a conservação e a valorização do valor-capital, repousam na expropriação e na depauperação das grandes massas de produtores, não importando as formas que emprega para conseguir os seus fins, levando ao aumento ilimitado da produção, para a produção, pela própria produção. Nessa lógica, compreende-se que não há limite para vencer a crise estrutural.

Como afirma István Mészáros

Os limites absolutos da existência humana - tanto no plano militar como no ecológico têm de ser avaliado "diante dos riscos [...] de uma destruição irreversível do meio ambiente, tornou-se imperativo criar alternativas práticas e soluções cujo fracasso é inevitável em virtude dos limites do capital que colidem com os limites da existência humana (MÉSZÁROS, 2011, pg. 123).

Entretanto como reflete esse autor,

A consciência dos limites do capital tem estado ausente em todas as formas de racionalização de suas necessidades reificadas, e não apenas nas versões mais recentes 
de ideologia capitalista. Paradoxalmente, contudo o capital é agora compelido a tomar conhecimento de alguns desses limites, ainda que evidentemente de uma forma necessariamente alienada (MÉSZÁROS, 2011, p. 993).

Sob essa fundamentação, fica transparente o entendimento da relação sociedade-natureza, na qual está estabelecida a crise ambiental contemporânea e está tecida a análise da estrutura social, que a cria e é criada a partir do sistema econômico capitalista. Um sistema e uma sociedade que negam o homem enquanto natureza, remetem a crise ambiental a partir de uma concepção de natureza desumanizada posta no mercado de ativos econômicos. A consciência alienada no processo do trabalho é condição necessária para essa separação e negação do ponto de vista material, científico e da práxis, do processo sociohistórico que substantiva essa relação. Ao considerarmos a exorabilidade da relação sociedade-natureza inclui-se uma nova perspectiva para a elucidação do período atual, onde a produção e a reprodução social se realizam coordenadas por fenômenos globais, no qual o desafio reside pensar em que medida a questão ambiental existe como problemática. Ao problematizá-la, deve-se observar em que estrutura sociohistórica, socioeconômica e política ela se mantém e se organiza, para garantir a ampliação do processo de acumulação capitalista.

No campo ideológico, para a manutenção da hegemonia burguesa, através da tácita negação da razão emancipadora e pela necessidade de justificar teoricamente a forma de organização socioeconômica consolidada pelo capitalismo, o pensamento burguês faz-se emergir das teorias pós-modernas. Estas despontam enquanto expressões ideológicas nesta fase de acumulação capitalista, com a função de mistificar ideologicamente as determinações histórico-sociais, na medida em que buscam transvestir a crise do capital em crise ambiental, aprofundando o abandono da totalidade histórica e intensificando a exacerbação do relativismo e da fragmentação da realidade. A chamada para a catastrófica destruição da natureza, enquanto crise ambiental, localiza-se na ideologia pós-moderna, que apresenta complementaridade ao pensamento liberal na medida em que representa, no campo das ideias, a ascensão de um "ceticismo epistemológico e um derrotismo político profundos" (WOOD, 1998, p. 13) que, contribui para decretar a inevitabilidade do capitalismo em profunda sintonia com a teoria liberal e sua prática destruidora da natureza.

A destruição é a própria negação da natureza em sua sociabilidade. E é na sua restrição social que ela se impõe como exigência da sua condição de existência social (THOMAS, 1988). E também apresenta seu aspecto dialético específico, sua dinamicidade, sua simultaneidade, seu metabolismo (FOSTER, 2005). Não existe natureza sem seu aspecto metabólico, quer se trate da matéria (necessária ao sistema produtivo) ou do sentido simbólico. Mas o metabolismo destrói a si próprio por degradação, porque remete a um ritmo metabólico acelerado, produção de espaços exauridos e segregados. "A produção capitalista, portanto, só desenvolve as técnicas e o grau de combinação do progresso social da produção, minando simultaneamente, as fontes originais de toda a riqueza - o solo e o trabalhador" (FOSTER, 1999, p. 167).

Nesse movimento permanente, são alterados os domínios e as condições ambientais que sustentam a produção e a reprodução da vida, os modos de apropriação e usos do espaço, em que as 
contradições permanecem e ganham expressão de modo especial, nas lutas sociais urbanas, nas ações público-estatais e nas ações privadas dos mercadores de espaço (LEFEBVRE, 1974).

A propriedade privada da natureza nasce da expropriação e da dissociabilidade enquanto bem comum, para ser apropriada individualmente, egoisticamente e existir como capital. A propriedade privada dos meios de produção e da riqueza produzida é identificada como o momento causal da exploração e da alienação do trabalho (MARX; ENGELS, 1989). As fontes de valorização capitalista expõem o individualismo metodológico e a racionalidade ao transformar a natureza em recursos, separando-a em partes de valor e não valor. A natureza no capital tem sua expressão de valor mercadológico, do não valor de partes que não servem ao capital, seus rejeitos, e de não valor que serve como condição de uso. Segundo Altvater (2006), forma-se uma rede comum de valores consumista-individualista, em um mesmo mercado de trabalho, em que as desigualdades, a exclusão socioespacial e a destruição da natureza têm acentuado e ao mesmo tempo produzido espaços de resistência. No entanto, o alarme soa nesse sistema apenas quando determinados valores limítrofes são atingidos. Ainda assim, a natureza constituirá como bem disponível e desprovido de importância para o sistema, enquanto este puder obter acesso às reservas além de suas fronteiras.

A mercantilização da natureza evidencia a destruição como unidade interna da produção e da produtividade. Por isso, de acordo com Marcuse (1979), obscurece a própria destrutividade que se impõe enquanto crise ambiental no século XX e se antepõe às soluções advindas de mecanismos internacionais de regulação e intervenção instalados pela Organização das Nações Unidas (ONU), seja a partir de instituições reguladoras nacionais e/ou de um novo mercado verde global, travestido de bem comum. Este se coloca como um mercado em expansão, em disputa de competitividade, que opera independentemente da consciência humana e que subsume cada indivíduo a sua lógica. Esse modo econômico, para Moraes (1984), requalificou os espaços periféricos, identificou áreas de maior interesse pelo centro onde as zonas periféricas, na qual o Brasil se encontra, agregam a função fornecedora de produtos naturais, de produtos advindos da cultura de plantation e da exploração dos recursos minerais. Também é importante ressaltar, em pressupostos capitalistas, a inclusão social, a diminuição da pobreza, as tecnologias limpas, os ciclos de uso industrial fechados, a logística reversa e a diminuição de emissões atmosféricas que visam a eficiência no uso dos recursos naturais. Estes postos em escassez, podem ameaçar a continuidade das atividades empresariais.

O sistema de produção de mercadorias estruturalmente orientado pela busca da maior rentabilidade na acumulação de riqueza abstrata, conduz a espoliação e a degradação das condições naturais da qual depende visceralmente e choca-se com outras formas de apropriação social da riqueza natural, cujos efeitos deletérios são computados como crise ambiental. Para atingir a superprodução, segundo Casanova (2006), se faz pelo trabalho alienado, pelo superconsumo e pela apropriação privada dos meios de produção, através dos quais acelera-se o uso da natureza, a partir da compressão do ciclo produção-circulação-distribuição-consumo, que garante a acumulação privada da riqueza socialmente criada. 
A natureza é apropriada como importante mercado em expansão na forma concreta intensificada com os aportes tecnológicos a partir do valor-mercadoria transformado pelo trabalho e sob forma financeirizada, através do mercado financeiro. $\mathrm{Na}$ sua forma abstrata, a partir da economia financeirizada, a abstração se dá no processo de valorização do capital, estabelecida em ativos de créditos na balança comercial mundial, que dá vida e aquece o mercado verde. A partir dessa análise tecemos como objetivo central apresentar elementos relevantes à fundamentação e à compreensão da crítica acerca da apropriação capitalista da natureza, enquanto mercadoria e geradora da crise capitalista ambiental contemporânea, utilizando-se das categorias de análise; natureza com valor de uso, com valor de troca e a da forma financeirizada, como explicativa da relação sociedade-natureza no ciclo de produção e reprodução do capital. O artigo está organizado em duas seções: a primeira trata da condição concreta de realização das sucessivas separações e rupturas entre a sociedade e a natureza: apropriação, mercantilização e inscrição nos circuitos de exploração do capital como geradora da crise ambiental capitalista. A segunda seção consiste na análise específica sobre a peculiaridade da forma financeirizada de circulação do capital como qualificativo do processo de valorização capitalista inscrita nas economias verdes como conexão entre a crise ambiental capitalista e o sistema de crédito.

\section{Sociedade-natureza: apropriação da natureza, mercantilização e inscrição nos circuitos de exploração do capital}

$\mathrm{Na}$ história da humanidade, as formas da relação sociedade-natureza que têm na base de produção o sistema capitalista, este por seu caráter expansivo e ilimitado, estabelece as condições de superação dos limites como os entraves político-jurídico e culturais contrários à sua reprodução e ampliação. Enquanto sociedades anteriores impunham limites sociais à produção, considerando a satisfação das necessidades sociais de todos, portanto, a apropriação da natureza no seu valor de uso. É a incompatibilidade de apropriação social da natureza no capitalismo que carrega consigo o desequilíbrio ecológico à sua própria destruição, atinge proporções globais e fomenta a crise estrutural (MÉSZÁROS, 2011).

A relação sociedade-natureza em qual está estabelecida a valoração da natureza nos remete a análise da estrutura social que a cria e é criada a partir do movimento do sistema econômico capitalista. $\mathrm{O}$ modo específico de valorar a natureza enquanto mercadoria dá-se no processo de produção, circulação e consumo, mediante às formas econômicas de incorporação do valor, do mais valor e sua expressão abstrata, a forma financeirizada e expressa nas economias verdes. Essas economias absorvem as externalidades negativas, analisadas no âmbito das práticas da produção capitalista como apropriação diferencial da natureza-mercadoria no ciclo de rotação do capital. A contradição entre produção e realização de valor, assume a forma de produção de crises por superprodução do capital. O entendimento das fontes de tensões e crises geradas na produção só é possível a partir da concepção dialética e materialista entre a relação natureza-sociedade, como uma relação de contradição entre as unidades social e natural. 
Para Marx e Engels (1989), a história da humanidade, assim como para Mészáros (2011), é a história da produção de riqueza material e seu valor de uso, como a substância de toda a riqueza produzida, independente de qualquer forma social que esta venha a ter, estabelecendo a satisfação das necessidades básicas de existência como primeiro período histórico da sociedade, sendo o trabalho como condição natural da existência humana, intercâmbio entre a sociedade e a natureza. A partir da ruptura dessa relação, através do trabalho alienado, da separação histórica dos trabalhadores dos meios de produção e da apropriação desses meios por uma classe que explora a força de trabalho para produção de mais-valia, é que poderemos iniciar a compreensão da distinção do valor de uso e valor. Entretanto, a alienação pode ser compreendida, também, a partir da ruptura da relação homem-natureza e da ruptura enquanto ser social, pelo individualismo extremo e acirramento da competitividade no mundo do trabalho. O que vem a causar estranhamento dos homens entre si e com o produto de seu trabalho. "O trabalhador não se afirma no seu trabalho, mas se nega. Essa negação está no fato de o trabalho não ser um bem próprio do trabalhador, criar a dominação sobre a produção e sobre o produto por parte daqueles que não produzem" (OLIVEIRA et al, 2005, p. 145).

$\mathrm{Na}$ economia capitalista, como meramente mercantil, a sociedade somente poderá satisfazer suas necessidades de consumo através da transformação dos bens com valores de uso em valores de troca e com a reprodução da força de trabalho que se dá mediante aquisição de mercadorias.

A economia de mercado impede, assim, os indivíduos (ou detentores de casas) de se reproduzirem independentemente do nexo do mercado. Esta exclusão pressupõe que tanto individual como coletivamente, os produtores humanos não tenham acesso a algumas condições necessárias para produzir meios necessários para consumo fora do sistema de produção e troca de mercadorias, sem que essas necessárias condições de produção assumam a forma de mercadorias (BURKETT, 1999, p. 58).

A separação da relação sociedade-natureza e dos trabalhadores dos meios de produção, por expropriação, faze com que os trabalhadores fiquem "livres" para que vendam a sua força de trabalho, como valor de troca, em mercadoria. Essa torna-se a condição necessária para a universalização do trabalho assalariado sob o controle dos detentores dos meios de produção. A existência de outras formas de produção, como a camponesa, que preconiza a satisfação das necessidades e venda do excedente da produção, por não existir acumulação com o fim em si mesmo não se darão de modo hegemônico. Assim, “as condições naturais somente são úteis para o capitalismo na medida em que servem como veículo de exploração do trabalho humano, bem como de sua realização monetária” (BURKET'T, 1999, pg. 47).

Evidenciam-se as contradições do capitalismo, aprofundando essa condição ao separar, também, a natureza da sua unidade em partes como recursos naturais, constituindo valor de troca no mercado mundial.

Assim, como todas as formas de produção de riqueza humana, a produção capitalista é dependente da contribuição dos valores de uso provenientes da natureza (ver capítulos 2 e 3). Por outro lado, o capital requer a natureza apenas na forma de condições materiais "separadas" para sua apropriação de dos valores de uso da força de trabalho, não na forma de uma unidade social e material orgânica entre os produtores e as suas condições naturais de existência. Esta qualidade de "separação", das condições naturais para o capital, corresponde à separação social dos trabalhadores de condições 
necessárias de sua produção, isto é, à relação de classe fundamental do capitalismo (BURKETT, 1999, p. 58).

O valor de uso é uma contradição na unidade mercadoria. O valor de troca de uma mercadoria se define na relação desta com outra, ou seja, o valor de troca é uma contradição na unidade natureza. Isso permite caracterizar o valor de troca como puramente relativo, sendo essa relação mutável no tempo, no espaço, nas diferentes escalas das relações de produção.

\begin{abstract}
Uma coisa pode ser um valor-de-uso e não ser um valor: basta que seja útil ao homem sem provir do seu trabalho. Assim, acontece com o ar, prados naturais, terras virgens, etc. Uma coisa pode ser útil e produto do trabalho humano e não ser mercadoria. Quem, pelo seu produto, satisfaz as suas próprias necessidades, apenas cria um valorde-uso pessoal [mas não uma mercadoria]. Para produzir mercadorias, tem não somente de produzir valores-de-uso, mas valores-de-uso para os outros, valores-de-uso sociais. [E não basta produzir para os outros. Para ser mercadoria é necessário que o produto seja transferido para outrem, que o utilize como valor-de-uso, por meio de troca]. Finalmente, nenhum objeto pode ser um valor se não for uma coisa útil. 'Se for inútil, o trabalho que contém é gasto inutilmente, [não conta como trabalho] e, portanto, não cria valor' (MARX, 1988, V. I, p. 46).
\end{abstract}

O capitalismo requer que as condições naturais estejam postas em utilidade para seu desenvolvimento e extração de mais-valia. Tanto as condições naturais como o trabalhador somente são úteis para o capitalismo como veículos de exploração e sua realização monetária. A alteração da substância contida na relação sociedade-natureza manifesta sua contradição nas relações de trabalho, nas necessidades sociais de consumo e nas formas de organização social. Gestam-se e explicitam-se o caráter mercantilista no interior das contradições do valor de uso e de troca, no que concerne à substância e à determinação do próprio valor, da natureza.

[...] o valor é, antes de tudo, uma categoria social. Não há valor sem trabalho, em seu duplo significado: valor de uso e valor de troca. O primeiro expressa a substância mesma do valor, o seu fundamento material. Ele exprime a utilidade do produto para a satisfação das necessidades humanas [...] A medida real do valor de uso será, então, a quantidade de trabalho (expressa em tempo de trabalho) socialmente necessária para sua obtenção. Nesse sentido, a história humana, até o advento do capitalismo, é marcada basicamente pela produção dos valores de uso. Com a intensificação do comércio e da produção de mercadorias, a ênfase passará a ser produção de valores de troca. Contudo, os valores de uso continuam tendo uma existência real, só que agora como veículo do valor de troca (MORAES, 1984, p. 110).

A produção capitalista não se limita as necessidades pré-determinadas para manutenção dos vínculos da sociedade com a natureza, ela vai além desses limites, produzindo supérfluos como necessários, pondo o próprio valor-de-uso sob o controle da indústria em expansão.

A própria produção, em toda a sua estrutura, esta orientada no sentido do valor-de-uso e não do valor-de-troca, e só quando excedem os limites em que são necessários ao consumo os valores de uso deixam de ser valor-de-uso para se tornar meio de troca, mercadoria. Por outro lado, eles só se tornam mercadorias nos limites de seu valor-de-uso imediato" (MARX, 1988, V. I, p. 39).

A intensidade e variedade dos desejos no sistema capitalista são determinados pela produção. E a produção é impulsionada pela distribuição e consumo. Existe um aspecto compulsivo desse sistema de realizar cada vez mais trabalho excedente. Casseti (1999) observa que a incorporação de tecnologias ao 
processo produtivo industrial, combina ações científicas com econômicas, sociais, políticas, entre outras, que acabam por culminar na estruturação de um espaço de realidades com muitas desigualdades, tanto do ponto de vista social e econômico, quanto de sua expressão material.

A associação entre a ampliação do conhecimento científico e a elaboração de tecnologias submetem a natureza e o trabalho para aumentar a produtividade do trabalho e, consequentemente, a produção de mercadorias. Ocorre a institucionalização da racionalidade econômica para aperfeiçoamento dos meios de produção e qualificação do trabalho, que é incentivada pela necessidade ampliada de expansão do capital. Isto possibilita novas descobertas de matérias primas e fontes energéticas que reduzem o custo e criam novas demandas. A mercadoria torna-se a forma unificada dos trabalhadores com os meios de produção. Sob tais princípios econômicos, o capitalismo esbarra nos seus limites com a possibilidade de esgotamento de certas reservas naturais. Esta possibilidade faz com que o capitalismo produza necessidades constantes de autorreprodução e expansão, dirimindo barreiras que evoluem na lógica monetária e criando formas de preservação da natureza para sua autopreservação.

Altvater (1995, p. 29) acrescenta que

O moderno sistema industrial capitalista depende de recursos naturais numa dimensão desconhecida a qualquer outro sistema social na história da humanidade, liberando emissões tóxicas no ar, nas águas e nos solos e, portanto, também na biosfera. Nestes termos, necessita de recursos naturais (energias e matérias-primas e também cada vez mais das fontes genéticas localizadas, sobretudo no Sul) e precisa de recipientes (locais de despejo onde os rejeitos gasosos, líquidos e sólidos possam ser absorvidos ou depositados).

Um mercado mundial se instala no discurso do compromisso de assegurar as condições naturais e sociais de existência, reduzindo o aspecto destrutivo no processo produtivo das economias. Porém, no mercado de capitais as empresas têm a necessidade de se manter competitivas e, caso uma ação ecologicamente e socialmente correta não gere resultados financeiros, esta é imediatamente cortada das políticas empresariais. As energias ditas limpas são destas economias estimuladas como ativos para novos nichos de mercado global.

Os problemas ambientais urgentes, tais como os de mudanças climáticas, estão cada vez mais sendo vistos como oportunidades de inovação, estímulos a novos produtos, processos, mercados e modelos empresariais. Orientadas por multiplicidade de fatores - concorrência, medo de intervenção governamental, pressões ativistas, exigências de clientes, altas nos preços de energia, preocupações de acionistas, mudanças de expectativas públicas, necessidade de atrair e manter bons profissionais -, as empresas estão utilizando tais oportunidades para a criação de valor nos negócios, ao mesmo tempo em que melhoram seu desempenho e reputação (MAKOWER, 2009, p. 1).

No período histórico em que o avanço das forças produtivas estabelece um aprofundamento das contradições através do aparato tecnológico e propõe mediação e conciliação com o trabalho, existe um novo processo de dominação ainda em curso, a forma financeirizada e desregulamentada de valoração abstrata da natureza, que entra em choque com o velho modo mecanicista, fordista de produção regulada. É a captura da dinâmica contraditória, entre o trabalho produtor de mercadorias e o tempo, para reduzir o ciclo de produção e acumulação, que a sociedade do capital pretende superar o tempo de produção e reprodução da natureza, enquanto condição de fornecedora de matéria prima, na medida em que esta é 
valorada não na sua condição de existência mas na sua condição de valor-mercadoria. Esta forma de conceber a natureza pode ser medida em termos de abundância e escassez, e também na sua forma abstrata, processual, no vir a ser. O valor-mercadoria se constitui a forma estruturante da sociedade do capital em sua relação com a natureza, mediada pelo trabalho alienado e centro da vida individual.

A situação histórica da sociedade contemporânea inscreve os postulados dos clássicos que advogam o mercado como o mais sensato mecanismo para coordenar a multiplicidade de interesses, decisões e ações individuais. O mercado, cada vez mais competitivo, se apresenta como a condição para o homem tornar-se um ser supremo; como a forma única de produção e de distribuição da riqueza social. O mercado é necessário para que o homem encontre alternativas que melhorem a sua condição social, já que a troca se constitui a única maneira de alcançar o que deseja através da liberdade de agir (LISBOA, 2007).

No sistema do capital, a existência do mercado é necessária para a demanda efetiva de políticas de favorecimento às transnacionais. $\mathrm{O}$ mercado instrumentaliza o Estado e este o instrumentaliza sob o comando das instituições financeiras internacionais, que determinam a ampliação de maiores lucros, via formas de gestão e fluxos, induzindo sempre em maior intensidade à ampliação da produção de valores de troca, em que o objetivo é o lucro. Na lógica da crise do capital, não importam os limites para recompor a tendência crescente da taxa de lucros (CONCEIÇÃO, 2017).

$\mathrm{Na}$ lógica do mercado competitivo a natureza só interessa na medida em que pode ser convertida em valor monetário. Nessa perspectiva, o ar, a água, o solo, a floresta e os animais não são elementos fundamentais para manutenção do equilíbrio ecológico, nem elementos fundamentais na manutenção da vida social, são um conjunto naturalmente produzido de matérias-primas, meios e condições que podem ser utilizados para acumulação única da quantidade que conta, a monetária.

A concorrência precipita os capitais individuais numa luta de vida ou morte pela externalização dos custos de produção e de provimento das condições de produção. Assim, como efeito não pretendido, orquestrado por uma mão maligna, mão invisível, verdadeira tragédia dos comuns, crescem continuamente os custos das tarefas de provimento das condições naturais da produção, tarefas que, evidentemente, devem ser operadas pelo Estado e custeadas pela tributação de parcelas crescentes do valor excedente produzido (CARNEIRO, 2005, p.29).

A mediação da degradação ambiental passa a exercer valor não só da natureza explorada através do trabalho social e apropriada individualmente, mas da natureza a ser recuperada. Essa medida socializa os desequilíbrios e a poluição e individualiza os ganhos, quando se propõe estipular valor da natureza degradada (rio poluído, floresta devastada, solo contaminado, entre outros) e sua recomposição ou recuperação através de técnicas e tecnologias ditas modernas que ativam um mercado tecnológico alocados em países hegemônicos.

Vê-se, então, a formação de novos circuitos de valorização da natureza, novas estratégias de reapropriações privadas dos processos produtivos e novos sentidos que mobilizam e reorganizam a sociedade aos propósitos dos circuitos do capital, diminuindo o espaço-tempo de produção e destruindo todos os outros propósitos não mercantilistas da relação sociedade-natureza. 
A valorização de bens e serviços advindos da natureza revela a intenção dos agentes financeiros individuais. No caso de investimento na bolsa de valores de créditos de carbono comercializáveis, a linguagem é expressiva, os investidores colocam ou retiram seus dinheiros no mercado financeiro que aumenta magicamente.

O estabelecimento de valores econômicos exige a desvalorização de todas as outras formas de vida social. Essa desvalorização transforma em um passe de mágica, habilidades em carências, bens públicos em recursos, homens e mulheres em trabalho que se compra e vende como um bem qualquer, tradições em fardo, sabedoria em ignorância, autonomia em dependência (ESTEVA, 2000, p. 61).

O Estado dispõe da prerrogativa do poder de jurisdição substituindo os vínculos sociais, tradicionais e locais pelo poder da economia de mercado com a ajuda da criação de uma superestrutura político-jurídica que cuida continuamente das relações sociais, do caráter vinculatório do direito à natureza, de forma a assegurar o monopólio da coação legítima. Ocorre que a expansão contínua da atividade estatal amplia a aplicação de instrumentos de comando, controle e punição. Políticas ambientais consideradas duras dadas à normatização e controle do uso da natureza, se estabelecem na contramão do contexto atual de uma economia de acumulação mundializada. Nesse sentido, a mundialização da economia logra libertar-se das políticas de normatização duras para uma linha flexível liberando-se da sanha tributadora do Estado e da sua regulação política adotando mecanismos de mercado. E, ainda, instaurando programas de desregulamentação e austeridade a essas economias como essencial para assegurar a concorrência global. A modernidade sofre déficit institucional para a modernização da economia em que a transnacionalização dos mercados e das inovações tecnológicas transformaram a racionalidade instrumental na racionalidade predominante e suas exclusões/externalidades em um mal a ser atenuado.

À medida que a acumulação de riqueza abstrata logra libertar-se dos entraves para sua expansão se estabelece em crises posto que não há mais possibilidade de mecanismo de regulação estatal que freia a possibilidade de colapso inerente ao capital quando estabelece as condições gerais necessárias à continuidade do processo de acumulação. O’Connor (2012), observa que diante da crise capitalista, a ecologia cria a perspectiva da economia de meio como via alternativa à produção. $\mathrm{O}$ autor enfatiza a contradição entre as forças produtivas e as relações de produção e entre estas e as condições da produção em que a escassez da natureza estabeleceria formas sociais entre o capital e o Estado. Enquanto que o surgimento de movimentos sociais de proteção seria uma barreira social para o capital se expandir. Para Carneiro (2005), o capital mundializado estando livre de regulação corrói as suas próprias condições de acumulação, destacando as condições naturais da biosfera planetária que são também condição para a vida geral.

Assim, podemos compreender por que as tentativas de efetivar o controle e o direcionamento político da economia global, ocorridas nas conferências mundiais patrocinadas pela ONU, estão sempre longe de produzir sequer a diminuição do ritmo de deterioração das condições naturais do planeta. Os ambientalistas que, impregnados do iluminismo da ideologia do desenvolvimento sustentável, lamentam a falta de vontade dos soberanos, ignoram os travamentos estruturais que tornam imponentes e a 
pretensão de corrigir politicamente o programa ecologicamente suicida da economia (CARNEIRO, 2005, p.36).

Nesse contexto, de razão instrumental da ideologia iluminista é que a pauta ambiental começou a ganhar o reconhecimento do campo científico e técnico e com ela esse campo começa a se fazer mais complexo à medida que é captado por um discurso técnico-científico objeto de duras críticas. A ecoeficiência e a valoração abstrata da natureza vão dar sustentação ao surgimento de economias verdes para fins de preservação que se afinam com a fase de abstração do desenvolvimento capitalista e introduz no debate social a possibilidade de uma via mercantilizada, cada vez mais alienada da sociedade como forma de salvaguardar uma natureza em destruição. O sistema capitalista em sua forma mercantil procura desvincular o crescimento econômico da degradação ambiental estabelecendo as bases teóricas e econômicas que servem ao aprofundamento da exploração e manutenção desse processo (FONTENELE, 2013).

A forma subvertida que o capital executa ao estabelecer valor a natureza, seja através da transformação em mercadoria mediada pelo trabalho, ou na forma de ativos para a produção e expansão do sistema destroem a natureza. Sendo o capital, valor que se valoriza, ele estabelece e tipifica suas formas específicas de atuação fundadas no valor, que se concretizam na escolha da localização dos investimentos, pelos financiadores (FMI, BM). Esses investimentos são feitos a partir dos níveis de rentabilidade de capital e nas formas de obtenção de lucro na esfera financeira mundial, que se inserem, segundo Harvey (2013), como parte do contexto neoliberal, logo, só há investimento de capital onde se pode obter vantagens competitivas.

Os limites naturais impostos à expansão do capitalismo, à sua dinâmica compulsiva e incontrolável tendem a expandir ainda mais a separação social com o tempo e o controle da produção, além de acelerar a própria divergência da relação sociedade-natureza. Essa divergência impossibilita qualquer caminho de coexistência entre a lógica de produção capitalista e a lógica da natureza social sem que haja destruição de ambas a partir da ruptura do seu aspecto sociometabólico. É a partir dessa ruptura, livrando-se das barreiras em sua versão liberal, que a natureza-mercadoria se inscreve nos circuitos do capital mundializado.

\section{Economias Verdes e a Forma Financeirizada de Circulação do Capital}

No início do século XX, amplia-se o debate que a economia deve acompanhar os ritmos naturais para a produção da "riqueza real" em contraposição à "riqueza manufaturada" produzida pelo esgotamento do meio ambiente.

Investia-se assim na busca de uma economia de meios, porém não se discutia a natureza dos fins para os quais estes meios eram mobilizados; ou seja, não se refletia sobre o conteúdo mesmo do projeto desenvolvimentista. Economizar matéria e energia por uma revolução da eficiência: eis o caminho que era assim proposto para prolongar no tempo um desenvolvimento que, em seus próprios termos, era inquestionado (PORTO-GONÇALVES, 2006, p. 78). 
A utilização dos termos da física termodinâmica aproxima a análise do problema ambientaleconômico para a ideia de metabolismo na relação sociedade-natureza, tendo em vista que qualquer processo de transformação material é associado a um aumento irreversível de entropia. Altvater (1995) expõe que o sistema, o modo de produzir e de viver encontrarão inevitavelmente um fim quando o aporte de energias fósseis estiver esgotado ou quando as emissões tóxicas superarem o limite do suportável das esferas naturais.

A economia dos meios que tenta relativizar-se nos limites naturais choca-se com um mercado autossuficiente, em que o capital é valor em expansão que captura a própria lógica da sociabilidade de tal maneira que as categorias abstratas - valor, valor de uso - explicam a mercadoria e as relações mercadológicas que a constituem. O valor é uma propriedade interior à mercadoria, expressão das relações sociais existente e "[...] uma categoria da essência da sociedade capitalista, o valor de troca é sua forma de manifestação e aparece na superfície mesma dos fenômenos [...]" (CARCANHOLO, 1998, p. 19). Como o valor se constitui por trabalho social em abstrato, o capital é o trabalho social se autovalorizando de forma descontrolada e controlando toda a sociedade e sua relação com a natureza ${ }^{5}$.

O crescimento espetacular das transações financeiras foi um fator mais significativo da década de 1980 e já marcou os primeiros anos da década de 1990. Efetivamente, a esfera financeira representa a ponta-de-lança do movimento de mundialização da economia; é nessa esfera que as operações de capital envolvem os montantes elevados; é aí que sua mobilidade é maior; é aí que, aparentemente, os interesses privados recuperam mais completamente a iniciativa, em relação ao Estado (CHESNAIS, 2003, p.11).

Cerca de 160 países, entre eles o Brasil, faz uso dos empréstimos do Banco Mundial segundo suas disposições estatutárias todas as nações podem aderir-se ao Banco Mundial, contudo as exigências estabelecidas para a aceitação dos países membros fundamentam-se em critérios políticos ditados pelo FMI como aceitação do seu código de conduta (OLIVEIRA et al, 2005).

A avaliação que se faz da atuação do Banco Mundial é contrária aos seus discursos devido a sua contribuição para o desenvolvimento desigual e combinado das nações assistidas. "[...] a avaliação da performance do Banco Mundial é extremamente negativa. Este financiou um tipo de desenvolvimento econômico desigual e perverso socialmente, que ampliou a pobreza mundial, concentrou renda, aprofundou a exclusão e destruiu a natureza" (SOARES, 2003, p.17).

O Banco Mundial foi criado na Conferência de Bretton Woods, entre 1 e 22 julho de 1944. Nessa reunião, foi discutida a proposta inspirada por Keynes, o pai da "revolução keynesiana", para a criação pela primeira vez na história de uma organização permanente de caráter supranacional que regulasse o sistema financeiro internacional. O resultado da reunião de Bretton Woods foi a criação de duas organizações supranacionais, uma batizada de Banco Mundial para a Reconstrução e o Desenvolvimento (BIRD) e a outra de Fundo Monetário Internacional (FMI). Os empréstimos de capital são sempre em troca de juros e o banco faz a intermediação entre investidores e beneficiários (PEREIRA, 2010). 
Esse processo de financeirização, segundo Carneiro (2005), transformou a natureza pela mediação das relações de produção determinadas e específicas. E qualquer prática emancipatória dentro do contexto da lógica de mercado de capitais é levada a cabo pelas políticas neoliberais. Essas políticas condicionam a magnitude, a qualidade dos impactos e a destruição que a atividade econômica exerce na natureza, exatamente por condicionar a forma e os fins com que a sociedade, dividida em classes, organizam sua produção material e seu intercâmbio com a natureza.

Ao exercer o controle do território pelos ativos de mercado o capital pode permitir ou impedir o uso de riquezas naturais, criar monopólios dessas riquezas, normatizando atitudes e comportamentos em relação às atividades produtivas. Esse controle funciona como forte instrumento mediador e regulador do qual o Estado se utiliza para ordenar o espaço geográfico nacional, eliminando barreiras espaciais, estabelecendo conflitos em torno dos direitos territoriais e significados culturais que ultrapassam as tentativas de valoração econômica da natureza, na medida em que nega a condição de sujeitos às comunidades atingidas que vivem do próprio trabalho. Ao tempo, em que há emprego de capital para fins de restauração das condições da natureza e mediação dos conflitos sociais, que tendem a levar a crise para o capital financeiro implicando na redução dos custos da força de trabalho.

O Estado reificado desconhece qualquer direito não capitalizado, foca na ecologia instrumental, na modernização ecológica, na técnica e na tecnologia que vão estabelecer as estruturas para que o mercado financeiro da natureza apresente uma nova economia dos meios, a economia verde. O mercado verde para o capital atua como condição para liberação de crédito, tanto para a classe trabalhadora em projetos agroecológicos quanto para megaprojetos ditos sustentáveis. A instituição financeira condiciona a liberalização de crédito para os projetos, a regularidade junto aos órgãos do meio ambiente. Os projetos são tipificados como: de infraestrutura e energias (estradas, hidroelétricas, parques eólicos, termoelétricas, centrais de tratamento de resíduos industriais e domésticos, etc.), de commodities (agropecuária, mineração e siderurgia, papel e celulose, petróleo e gás) e de agricultura familiar financiados pelo BNDES ${ }^{6}$. Estes, como captação ideológica perante aos atributos de mercado, a partir de suas contradições para realização no consumo dos produtos da economia verde.

Os projetos agroecológicos ao tentar se contrapor ao agronegócio percerbe-se uma submissão da agricultura familiar aos preceitos da ideologia burguesa, onde a aquisição de tecnologia torna-se um determinante na relação capital x trabalho e a "qualificação profissional" leva a uma progressiva diminuição entre as diferenças das forças de trabalho tendendo a "massificação" da classe trabalhadora num ente uniforme e submisso aos projetos financiados pelo BNDES.

Os megaprojetos instaurados no País têm na sua estrutura o aspecto destrutivo da natureza para o contínuo processo de acumulação do capital, como, poluição ambiental, aumento da concentração de renda, destruição de postos de trabalho, expropriação, segregação, controle de quase $80 \%$ do mercado do setor alimentício, internacionalização de empresas, controle dos recursos naturais (florestas, água, terra, minérios, ar, etc.) e do próprio banco, os quais compõem o cerne do mercado. Essa é a saída do capital para redução do tempo de produção e circulação de mercadoria na produção de mais-valia. 
As decisões políticas ancoradas no discurso verde transformam em questões técnicas, mercadológicas em contradições sociais, que obstruem os controles democráticos da sociedade política. E entendem o território como propriedade na lógica mercantil atribuindo ao mercado a capacidade de resolver a degradação ambiental, o envenenamento dos alimentos por meio de medidas mitigadoras, compensatórias, incentivos fiscais e financeiros, tão caros as economias verdes.

Os partidários da modernização ecológica promovem uma despolitização da crítica ambiental, tão claramente articulada pelo movimento da ecologia política desde os anos 1970 ao desconsiderarem a articulação entre degradação ambiental e injustiça social. Naturalizando, assim, a crítica ecologista que demanda por mudanças na distribuição do poder sobre os recursos da natureza (ZHOURI et al., 2005, p. 53).

Os instrumentos da economia verde servem aos ajustes de mercado, quando promovem incentivos fiscais como, os ICMS verdes, bolsas verdes, selos de qualidade, isenções fiscais e incentivos financeiros a exemplo dos pagamentos por serviços ambientais, projetos de energias renováveis, preservação de florestas, produtos recicláveis, logística reversa, projetos culturais, etc.

Como proposta ideológica aos instrumentos da economia verde o Estado firma compromisso com o Banco Mundial e com o FMI para incorporar a política educacional à política do capital financeiro e passa a se organizar segundo as regras dos organismos financiadores elaborando suas propostas curriculares frente à educação para todos com intenção de formar um sujeito empreendedor, criativo, competitivo, apto às mudanças constantes. A escola assume a tarefa de preparar os indivíduos para se manterem sempre aptos a aprender aquilo que for necessário em determinado contexto e momento de sua vida (DUARTE, 1986).

Dantas (2011) expõe que o sistema estabeleceu um equilíbrio instável que tomou forma como um período marcado pela franca expansão do capital financeiro decorrente da ação do Estado rentista norte-americano, no sentido de desmontar as barreiras à circulação do capital, em especial às frações do capital financeiro. Os investidores e as instituições financeiras internacionais construíram um conjunto de mecanismos com o objetivo de fazer fluir em direção aos mercados financeiros um fluxo de riqueza que satisfizesse as exigências da economia internacional ignorando as condições de produção e de realização do valor.

Chegamos em um sistema que a produção, os meios de produção e os meios de trabalhos social são hoje do capital em sua forma financeirizada. Eles só serão utilizados e ampliados se seus proprietários (os acionistas financeiros), considerarem que vão tirar desta operação um lucro suficiente e valor acionário à altura de suas exigências (CHESNAIS, 2003). Percebe-se que quanto mais crítico e destruidor se torna o desenvolvimento das forças produtivas capitalistas mais aumenta a penetração do capital financeiro metamorfoseado na Economia Verde como salvaguarda da natureza e sociedade.

A edificação desse novo regime de acumulação com dominância financeira é formada no setor produtivo, a partir de onde assume a forma de rendimentos na produção e no intercâmbio de ativos de mercado. O que ocorre atualmente é que uma parcela cada vez mais elevada desses rendimentos é direcionada para a esfera financeira. "O regime financeirizado se constitui em um passo além do 
movimento de esforço e expansão da propriedade privada. Quanto mais áreas estiverem sobre o império desta, mais oportunidades se abrem para o rentismo [...]” (LAPYDA, 2011, p. 101).

O Estado impõe uma legislação que garante a propriedade e cria um novo mercado regulatório internacional das atividades poluidoras e degradantes a partir de um mecanismo perverso que quanto maior a degradação maior o valor dos serviços ambientais. Em uma conta de ativos econômicos realizados pelas empresas capitalistas, em que a degradação da natureza e a consequente morte de trabalhadores por destruição de meios de vida de toda uma sociedade, se dão pela vantagem competitiva de perdas e ganhos no mercado mundial financeirizado.

Esse mercado faz com que seja mais vantajoso a prática do crime como assunção do crime consciente; a exemplo do comportamento da empresa Vale, uma das maiores multinacionais do país, com cerca de 55.000 funcionários, passados dois anos do crime por desabamento da barragem de rejeitos minerários, ocorrido em 25/01/2019, em Brumadinho, Minas Gerais, que levou a morte por sufocamento 272 pessoas e a destruição de toda a condição de vida da população local, no maior desastre ocorrido nesta década, teve seus ativos aumentados. Na semana que se seguiu ao desastre, a mineradora perdeu $26 \%$ do valor de mercado, porém no início de janeiro 2020, teve alta de 30\%, superando o valor anterior a tragédia. Os ganhos foram impulsionados por uma elevação média no preço do minério de ferro em torno de $36 \%$, em 2019. O valor do lucro foi superior ao valor pago pelo desastre em indenizações, reparações e medidas emergenciais. Configura-se, assim, a naturalização dos crimes ambientais à medida em que estes podem se inserir na valorização do capital, através de ações políticas, de arranjos e ajustes tecnológicos no âmbito da lógica econômica em qual se propõe resolver toda a problemática da degradação ambiental.

Nessa direção os órgãos reguladores são chamados a ordem para conter toda sanha devastadora da economia predatória, que submete a sociedade em uma postura de distanciamento da natureza, contribuindo para alienação, favorecendo a mercantilização e a possibilidade de novos desastres. Tal abordagem, leva à aplicação de condicionantes ambientais regulatórias, de incentivos econômicos ou estímulos de mercado, em que a valorização econômica torna-se a única forma legítima da representatividade da natureza. Essas condições possuem bases no poder imperialista mundializado com ações de curto prazo que não diminuem a degradação, nem a exploração excessiva da natureza apenas posterga o colapso. Como expõe Forster, 2005, p.166.

Do ponto de vista de uma forma econômica mais alta da sociedade, a propriedade privada do globo por indivíduos isolados parecerá tão absurda quanto a propriedade privada de um homem por outro. Nem mesmo uma sociedade inteira, uma nação ou mesmo todas as sociedades simultaneamente existentes juntas são proprietárias do globo. Elas são apenas posseiras, suas usufrutuarias e, como boni patres famílias [bons pais de família] devem legá-lo, em melhores condições, às gerações futuras.

O sistema capitalista tende a ajustar os fatores de produção à política ambiental proposta pela Organização para Cooperação e Desenvolvimento Econômico (OCDE) a partir de 1972, qual seria a de apoiar um crescimento econômico duradouro e contribuir para o crescimento do comércio mundial. Inclina-se a orientação internacional da economia capitalista para a adoção de instrumentos econômicofinanceiros no uso dos recursos naturais, os quais trarão maior flexibilidade à economia mundializada. 
Visualiza-se um novo cenário institucional sob o qual a valoração da natureza na esfera financeira vai aos poucos se impondo com o surgimento de novos sujeitos sociais e econômicos. Mesmo com a autonomização da esfera financeira em relação à esfera de produção e o controle do Estado,

[...] não se defende que a produção de mercadoria deixa de ser fundamental para a reprodução do capitalismo, o que estaria em flagrante desacordo com a realidade imediata, sobretudo no que se refere ao esgotamento dos recursos naturais e à crise ecológica decorrentes das resistências a qualquer limitação da produção. Trata-se de reordenação da lógica geral de acumulação do capital em prol da valorização financeira - cuja base está evidentemente no seu incrível aumento quantitativo -, que se reflete na produção de mercadorias como uma submissão desta aos objetivos do funcionamento da esfera financeira (LAPYDA, 2011, p. 46-47).

Os valores de mercado referem-se aos custos externos do processo de produção ao meio ambiente, os quais seriam repassados para o governo na forma de uma taxa equivalente ao custo marginal de controle da poluição emitida pela empresa. $\mathrm{Na}$ realidade, os valores estabelecidos para esse instrumento não se baseiam nos custos que a externalidade causa para o meio e para a sociedade porque isso exigiria o conhecimento da função do dano do poluidor, mas como valores estabelecidos pelos órgãos ambientais, para atingir os seus objetivos regulatórios de comando e controle estabelecidos legalmente (VARELA, 2008).

Este princípio é a base para o enfoque econômico da política ambiental (BURSZTYN; PERSEGONA, 2008). Essa corrente entende que os danos causados se devem aos custos não considerados no processo produtivo. Dessa forma, os recursos como água, solo e ar que recebem resíduos dos processos produtivos e não são comprados, entram na composição de mercado por compensação ambiental através dos instrumentos econômicos. Nesse caso os usuários em geral dos recursos naturais e não somente os poluidores devem pagar pela utilização desses recursos. Há uma socialização da poluição não só quanto ao custo mas também quanto à qualidade do ambiente.

As taxas mais comuns são as cobradas sobre efluentes na água, ar e solo, as quais, para a definição da cobrança são levadas em consideração as quantidades dos poluentes emitidos, independentemente do dano causado pela emissão. As taxas dos produtos que incidem sobre os bens no processo de produção ou consumo geram danos ao meio ambiente. Porém, as taxas sobre os usuários que contabilizam o custo do tratamento público dos efluentes e a cobrança de taxas diferenciadas, permitem que sejam cobrados valores menores para produtos e produtores ditos mais "favoráveis" ao meio ambiente.

Observa-se a preocupação com a mudança de atitude em termos de regulação ambiental, mudando de um modelo mais repressivo para um mais flexível no sistema capitalista. Essa atitude estabelece à remoção de obstáculos incômodos ao desenvolvimento sem destacar o fator de exploração que fica escondido sob o véu dos direitos liberais. A questão pauta-se nos valores normativos de limites impostos pelo mercado em acomodar compromissos e exigências ditas democráticas, prometendo qualidade de vida, removendo riscos ao adotar normas de emissões e outras leis para salvaguardar o ambiente. No entanto, seria difícil para ambas as partes negociarem quando os interesses econômicos 
estão ameaçados. Os mecanismos reguladores do mercado mundial atuam de modo tal que os privilégios da sociedade industrial afluente não sejam ameaçados.

Altvater alerta que,

[...] O meio ambiente não constitui fator restritivo enquanto a sua solicitação em relação à capacidade de absorção dos ecossistemas globais é pequena. Mas uma sociedade industrial capitalista é expansiva no tempo e no espaço; ela se amplia, aceleradamente. O alarme soa no sistema apenas quando determinados valores limítrofes são atingidos. O meio ambiente constituirá um bem disponível e desprovido de importância para o sistema enquanto sistemas fechados puderem obter acesso às reservas de outras regiões além de suas fronteiras [...] ao mesmo tempo, a natureza externa tem como fonte de matérias-primas e depósito de emissões uma capacidade de absorção da energia solar e, portanto, de produção de biomassa (ATVATER, 1995, p.33-34).

A defesa dos instrumentos econômicos é geralmente baseada na argumentação de que sua essência reside no funcionamento do mercado, permitindo simultaneamente a flexibilidade de resposta por parte dos agentes poluidores às exigências do Estado. Cria-se então um mercado de poluição, de licenças de emissão comercializáveis, certificados de redução de emissão de direitos de poluição e de direitos de utilização dos recursos. Para evitar a interpretação e a ira da sociedade de que as empresas possam adquirir direitos de poluir e socializar a poluição faz-se uso da denominação de permissões de emissões negociáveis. O que ocorre verdadeiramente é uma negociação dos conflitos territoriais no direcionamento das políticas de desenvolvimento.

Hoje, existe certa unanimidade no reconhecimento de que as sociedades desenvolvidas chegaram aos seus limites ecológicos. Sobretudo, a aceleração dos processos produtivos e o aumento de bens e mercadorias, disponíveis por meio da industrialização, não trouxeram o esperado melhoramento do bem-estar para grandes parcelas da população. A implementação de programas de desenvolvimento em muitos países foi acompanhada de graves conflitos nas zonas rurais e nas favelas urbanas (LASCHEFSKI, 2005, p. 248).

A financeirização ecológica sob as regras do FMI, BM, BIRD e OMC, instituídas pelo G7 junto às corporações transnacionais e outros detentores de capital financeiro, pode ser vista como uma nova forma de expansão e acumulação de capital em que os grupos financeiros dominam não somente os mercados, as principais redes comerciais locais e internacionais, mas também, a produção genética de alimentos, os alimentos agroecológicos, as fontes energéticas, os recursos hídricos e a disseminação de produtos culturais.

Os investidores e as instituições financeiras internacionais construíram um conjunto de mecanismos com o objetivo de fazer fluir em direção aos mercados financeiros um fluxo de riqueza que satisfizesse as exigências da economia internacional, ignorando as condições da produção e da realização do valor (DANTAS, 2011). No entanto, essas condições não podem ser satisfeitas de maneira estável enquanto dezenas ou mesmo centenas de milhões de pessoas de todas as partes do mundo são excluídas de prover suas necessidades individuais e coletivas.

"O regime financeirizado7 se constitui em um passo além no movimento de esforço e expansão da propriedade privada, quanto mais áreas estiverem sob o império desta mais oportunidades se abrem para o rentismo [...]" (LAPYDA, 2011, p. 101). Daqui se impõe uma legislação que garante a propriedade 
e cria um novo mercado regulatório internacional das atividades poluidoras e degradantes em um mecanismo perverso de serviços ambientais que abrem espaços para as economias verdes absorvidas pelo capital.

A economia verde advinda do poder imperialista mundializado não diminui a degradação nem a exploração excessiva da natureza, ela trabalha com mecanismos burocrático-institucionais e estruturais que lhe dão sobrevida. Esses são convertidos em produtos para o mercado financeiro que singulariza a participação social como controle local territorializado e importante instrumento para implantação das políticas pensadas globalmente. Assim sendo, a economia verde perde sua consistência e seu compromisso ecológico dando continuidade a centralidade do capital.

É importante, contudo, dar crédito às ações de produção ecológica que propõem a preservação da natureza em nome da continuidade da vida e de valorização do humano. A problemática consiste quando subvertem o discurso para produzir ações contrárias direcionadas a sustentação do capital.

\section{Considerações finais}

As categorias marxistas são atuais para um debate onde a crise ecológica se faz presente como uma anomalia para a ciência atual e em particular á ciência econômica e o poder político, questionando seus pressupostos e a lógica que fundamenta o sistema capitalista que é causa e consequência dos desafios ambientais vividos hoje.

A questão da razão e da ciência no socialismo, no sentido de Friedrich Engels no Anti-Dühring, diz respeito ao desenvolvimento das forças produtivas com maior produção do trabalho e ampliação da fronteira tecnológica. Planejamento no socialismo não diz respeito apenas ao nível econômico, mas a um processo de planificação da relação sociedade-natureza em todas as dimensões da vida social. A clássica análise de Engels do planejamento superando a anarquia de mercado e todas as irracionalidades do capitalismo contínua totalmente atual, especialmente, nesse período histórico de emergência climática, avanço do desastre ambiental e de ameaça a existência humana.

A economia verde ao nascer dentro de sistema econômico capitalista, tendo suas bases fundadas na exploração e alienação do trabalho, não é de fato ecológica pois o sistema no qual nasce é predatório em sua essência. Nos moldes que ela se apresenta não passa de uma retórica que consiste apenas em uma reestruturação do capital em busca de eficiência e novos nichos de mercado. A economia verde é uma exigência do capital para tornar o mercado autorregulado livre dos entraves para sua expansão. As ações de conservação e preservação da natureza estão sempre relacionadas com vantagens financeiras que justificam tais ações. Assim sendo, a economia verde perde sua consistência e seu compromisso com as soluções contra hegemônicas ao processo destrutivo do capitalismo, quando dispõe do poder político na mão do mercado estabelecendo o mercado autorregulado. Este mercado liberal aprofunda o encolhimento do espaço público dos direitos e dos bens públicos, enquanto amplia o alargamento do espaço privado dos interesses de mercado ao desviar o que é publico, destinados aos direitos sociais, para favorecer ao 
capital de tal maneira que esses direitos são privatizados e comercializados nos mercados aumentando exponencialmente a divisão social e a desigualdade de classes.

O problema que se lança é, em que momento histórico os preceitos da economia verde representam o rompimento com os paradigmas de uma economia predatória e privatizante que se apresenta como fomentadora da desigualdade socioeconômica. Ao analisar a relação sociedade-natureza na economia capitalista, deve-se verificar o real compromisso inscrito na busca por economias ecológicas para solucionar os desafios predatórios do sistema, seus limites e possibilidades. E se essa significa de fato uma nova economia ou apenas a transformação da economia tradicional que se adapta a novas condições de produção e as leis de mercado.

Altvater (1995), nos alerta que a sociedade capitalista utiliza as reservas naturais progressivamente como fonte de matéria prima para produção de mercadorias e como fonte de depósito de produtos indesejáveis. Tratam as limitações dos ecossistemas como entrave, comunidades tradicionais são vistas como concorrentes a serem eliminadas retirando seu meio de vida. Espécies de animais e vegetais são destruídas. "Deste modo o curso da evolução é influenciado por uma espécie, precisamente pelo homo sapiens, em uma velocidade jamais ocorrida antes da historia da vida na Terra" (ALTVATER, 1995, p. 30).

Através das categorias marxistas abrem-se espaços para a compreensão das estruturas que direcionam a economia verde e os instrumentos utilizados por ela para estabelecer valor a natureza dentro do sistema capitalista. A discussão da ideia de valor nos remete a economia clássica, apesar da economia verde muitas vezes transcender os parâmetros clássicos comerciais para expandir novas possibilidades de avaliação social. Porém, os caminhos traçados pela valoração da natureza passam pela compreensão das relações de poder e de garantias da propriedade privada determinadas pelo modo de produção capitalista.

Portando, precisamos questionar até que ponto o homem pode, realmente, agir com a consciência e liberdade na determinação dos valores ambientais, transigindo, quando necessário, a lógica do mercado e, principalmente, o modo (relacional) como se determina a produção do valor dentro do capitalismo. [...]

[...] Ainda assim, neste caso, a determinação do valor dependerá muito mais do poder e influência de alguns setores sociais, o que implicaria na submissão do meio ambiente á lógica social de apropriação capitalista e aos conflitos distributivos criados em torno da questão, campo de estudo para a Ecologia Política (SANTOS, 2015, p.38).

A partir do sucesso das estruturas sociais de dominação através dos instrumentos de mistificação e alienação do capital a realidade das contradições é muitas vezes naturalizada devido ao controle ideológico para sua consagração através da mercadoria. No entanto, como o capitalismo opera por crises em quais as contradições tornam-se mais visíveis mundialmente a partir do seu modo expansivo executado através de políticas de desregulamentação do mercado e de privatização dos recursos naturais, apontados como saída para o crescimento econômico e o desenvolvimento social. Essas medidas têm no seu aspecto contraditório a destruição da natureza em escala mundial, a partir da alienação do trabalho, da desmobilização da estrutura social, da ruptura das relação sociedade-natureza e da subsunção da natureza à realização na lógica do consumo. 
Compreende-se que a forma mercadológica e destruidora da natureza com a qual o capital exerce seu poder sobre a sociedade de classes está, estruturalmente, fundada na ruptura gerada no próprio metabolismo social da relação sociedade-natureza. Em virtude dessa separação, a sociedade não se reconhece enquanto natureza, por isso não advoga em sua defesa a não ser por meio de valor e numa relação de comando e controle. É a partir da condição alienada que a sociedade se constitui dentro do sistema capitalista e destrói as bases de sua própria existência. A superação dessa condição somente será possível pela "restauração metabólica" e pela "transcendência da alienação que caracterizam o sistema capitalista”, (FOSTER, 1999, p.27).

\section{Referências:}

ALTVATER, Elmar. Existe Um Marxismo Ecológico?, in A Teoria Marxista Hoje: Problemas e Perspectivas, orgs. Atilio Boron, Javier Amadeo e Sabrina González, Buenos Aires: Consejo Latinoamericano de Ciencias Sociales- CLACSO, 2006, p. 327-349.

ALTVATER, Elmar. O preço da riqueza. São Paulo: Unesp, 1995.

BURKETT, Paul. Marx and Nature. A red and green perspective. New York: St. Martin's Press, 1999.

BURSZTYN, Marcel; PERSEGONA, Marcelo. A grande transformação ambiental: uma cronologia da dialética homem-natureza. Rio de Janeiro: Garamond, 2008.

CARCANHOLO, Marcelo. D. A importância da categoria valor de uso na teoria de Marx. Pesquisa \&Debate, v. 9, número 2 (14), 1998. p. 17-43.

CARNEIRO, J. E. Política Ambiental e a ideologia do desenvolvimento sustentável. In: ZHOURI. A. (Org.). A insustentável leveza da política ambiental. Desenvolvimento e conflitos socioambientais. Belo Horizonte: Autêntica, 2005.

CASANOVA, P. G. Sociologia de la explotación. Buenos Aires: CLACSO, 2006.

CASSETI, Valter. Contra a Correnteza. Goiânia: Kelps, 1999.

CHENAIS, François; SERFATI, Claude. Ecologia e condições físicas de reprodução social: alguns fios condutores marxistas. In: Revista Crítica Marxista, n. 16. p. 1 - 40. São Paulo: Boitempo, 2003.

CONCEIÇÃO, Alexandrina Luz. Produção do Espaço e conflitos territoriais: expropriação da terra e exploração da natureza. In: SUERTEGARAY, Dirce Maria Antunes, et al. (Orgs.) Geografia e Conjuntura Brasileira. Rio de Janeiro: Consequência, 2017, p. 13-34; 38.

DANTAS, Gilson. Natureza atormentada, marxismo e classe trabalhadora. Brasília: Eautor, 2011.

DUARTE, Rodrigo A de Paiva. Marx e a natureza em O Capital. São Paulo: Edições Loyola, 1986. v. 4.

ESTEVA, Gustavo. Desenvolvimento. In: SACHS, Wolfgang. Dicionário do Desenvolvimento: guia para o conhecimento como poder. JOSCELYNE, Vera Lúcia; GYALOKAY, Susana de \& CLASEN, Jaime A. (Trad.). Petrópolis: Vozes, 2000, p. 59- 83.

FOLADORI, G. Los límites del desarollo sustentable. Montevideo: Ediciones de La Banda Oriental, 1999.

FONTENELE, Ana Consuelo F. Natureza, políticas públicas e (re)ordenamento do espaço: interfaces das políticas ambientais em Sergipe. 2013. 357f. Tese (Doutorado em Geografia) - Núcleo de Pós-Graduação em Geografia, Universidade Federal de Sergipe, São Cristóvão.

FOSTER, John Bellamy. A ecologia de Marx: materialismo e natureza In John Bellamy Foster; tradução de Maria Teresa Machado. - Rio de Janeiro: Civilização Brasileira, 2005. 
FOSTER, John Bellamy. Marx e o meio ambiente. In: Ellen Meiksins Wood; John Bellamy Foster. Em defesa da história: marxismo e pós-modernismo. Trad. Ruy Jungmann. Rio de Janeiro: Jorge Zahar Ed., 1999.

JAMESON, Fredric. A cultura do dinheiro: ensaios sobre a globalização. Petrópolis-RJ: Vozes, 2001.

HARVEY, David. Os Limites do Capital. Tradução: Magda Lopes. São Paulo: Boitempo, 2013.

LAPYDA, Ilan. A financeirização no capitalismo contemporâneo: uma discussão das teorias de FrancoiseChesnais e David Harvey. 2011. 223f. Dissertação (Mestrado em Sociologia) - Departamento de Sociologia da Faculdade de Filosofia, Letras e Ciências Humanas da Universidade de São Paulo, São Paulo.

LASCHEFSKI, Klements. O comércio de carbono, as plantações de eucalipto e a sustentabilidade das políticas pública - uma análise geográfica. In: ZHOURI, Andréa et al. A insustentável leveza da política ambiental: desenvolvimento e conflitos socioambientais. Belo Horizonte: Autentica, 2005. p. 89116.

LEFEBVRE, Henri. La production de l'espace. Paris: Anthropos, 1974.

LISBOA, Josefa B. de. A trajetória do discurso do desenvolvimento para o nordeste: políticas públicas na (dis)simulação da esperança. 2007. 272f.Tese (Doutorado em Geografia) - Núcleo de PósGraduação em Geografia, Universidade Federal de Sergipe, São Cristóvão.

MAKOWER, Joel. A economia verde; descubra as oportunidades e os desafios de uma nova era dos negócios. Trad. Célio Knipel Moreira. São Paulo: Editora Gente, 2009.

MARCUSE, Herbert. A ideologia da sociedade industrial: o homem unidimensional, 5 ed. Rio de Janeiro: Editora Zahar, 1979.

MARX, Karl. Grundrisse: Manuscritos econômicos de 1857-1858- esboços da crítica da economia política, tradução Marcos Duyaer. Nélio Schneider, São Paulo: Boitempo, 2013.

MARX. K. O Capital: O Processo de Circulação do capital. Tradução: Rubens Enderle. São Paulo: Boitempo. Livro II, 2011.

MARX, K.; ENGELS, F. A ideologia alemã. São Paulo: Martins Fontes, 1989.

MARX, Karl. O Capital. São Paulo: Nova Cultural. V.I, 1988.

MÉSZÁROS, István. A crise estrutural do capital. São Paulo: Boitempo, 2011.

MORAES, A. C. R. Fixação do valor e capital fixo. São Paulo: Boletim Paulista de Geografia, no 72, 1984, p. 83-93.

O'CONNOR, James. Capitalismo e meio ambiente. In: Revista Novos Rumos. São Paulo: Unesp, 2012. v. 21.

OLIVEIRA, Admardo Serafim de. et al. Introdução ao pensamento filosófico. 8a ed. São Paulo: Edições Loyola, 2005.

PEREIRA, João Márcio M. O banco mundial como ator político, intelectual e financeiro - 19442008. Rio de Janeiro: Civilização Brasileira, 2010.

PORTO-GONÇALVES, Carlos. W. P. Globalização da natureza e a natureza da globalização. Rio de Janeiro: Civilização Brasileira, 2006.

RAMOS, M. H. R. Desenvolvimento sustentável numa perspectiva crítica. 2010. Disponível em: $<$ http:/ $/$ www.redecomunaverde.org $/ \mathrm{rede} /$ index.php?option $=$ com_content\&view $=$ article\&id=68:dese $>$. Acesso em: 28 de julho de 2021.

SANTOS, Santos, Ronaldo Alencar dos. Natureza, alienação e capitalismo em Marx: uma crítica da sustentabilidade. 2015. 257p. Tese (Doutorado em Ciências Sociais) - Programa de Pós-Graduação em Ciências Sociais da Universidade Federal do Rio Grande do Sul, Natal-RN.

SOARES, Laura. T. O desastre social. Rio de Janeiro: Editora Record, 2003. 
THOMAS, Keith. O Homem e o Mundo Natural: mudanças de atitude em relação às plantas e aos animais - 1500-1800. Tradução: João Roberto Martins Filho. São Paulo: Companhia das Letras, 1988.

VARELA, Carmen A. Instrumentos de políticas ambientais, casos de aplicação e seus impactos para as empresas e a sociedade. Rev. Ciênc. Admin., Fortaleza, v. 14, n. 2, dez. 2008. p. 251-262.

ZHOURI, Andréa; KLEMENTS, Laschefski; PAIVA, Angela. Uma sociologia do licenciamento ambiental: o caso da hidrelétrica em Minas Gerais. In: ZHOURI, Andréa et al. A insustentável leveza da política ambiental: desenvolvimento e conflitos socioambientais. Belo Horizonte: Autentica, 2005. p. 89116.

WOOD, Ellen Meiksins. The agrarian origins of capitalism. In: SWEEZY, Paul; HUBERMAN, Leo (Ed.). Monthly Review. an independent socialist magazine. New York: Monthly Review Press, 1998. v. 50 , p. 14-31.

\begin{abstract}
Notas
${ }^{1}$ Doutora e Pós doutorado em Geografia. Professora de Educação Básica da Secretaria de Estado da Educação e Cultura de Sergipe (Seduc). Gerente de Avaliação de Estudos Ambientais (Geaia) na Administração Estadual do Meio Ambiente (Adema). Membro do Grupo de Pesquisa Estado, Capital, Trabalho (GPECT/UFS/CNPq) dgp.cnpq.br/dgp/espelhorh/5086215847724681 e da Associação de Geógrafos Brasileiros (AGB), seção Aracaju. Currículo Lattes: http://lattes.cnpq.br/2405574893726279 . Orcid: http://orcid.org/0000-0003-1790-8421 . E-mail: anaffontenele@gmail.com

${ }^{2}$ Doutora em Geografia (USP). Professora Emérita da Universidade Federal de Sergipe (UFS). Líder do Grupo de Pesquisa Estado Capital, Trabalho GPECT/UFS/CNPq - dgp.cnpq.br/dgp/espelhorh/5086215847724681. Professora do Programa de Pós-Graduação de Geografia/PPGEO/UFS. Currículo Lattes: http://lattes.cnpq.br/5086215847724681 Orcid: http://orcid.org/0000-0001-6610-6228.E-mail: alexandrina.luzconceicao@gmail.com

$3 \mathrm{O}$ debate para o que vem sendo denominada crise ambiental, no que se refere às suas consequências, é estabelecido no caráter conservador da sociedade moderno-colonial, final da década de 1970 e início de 1980, que assume ser possível reverter a atual situação de crise adotando-se o desenvolvimento sustentável como princípio estruturante do processo de desenvolvimento, com políticas conciliatórias de classe, normativas e de controle interno, executadas pelo Estado, de forma a resolver o viés destrutivo do ambiente natural que põe o desenvolvimento em perigo por destruição de suas próprias condições de funcionamento sem tocar no avanço do modo de produção capitalista. Para compreender melhor sobre sua origem, consequências, divergências, debates ver Ramos (2010) e no seu contraponto através da análise da ruptura metabólica do homem-natureza ver em Foladori (1999).

${ }^{4}$ Uma excelente discussão sobre o tema, com atenção especial para a natureza geral da dialética como ciência das relações em contraste com a metafísica, extraídas da história da natureza, assim como a história da sociedade humana, encontra-se no livro de Frederich Engels, a dialética da natureza (ENGELS, 2000).

5 A partir dessa análise fica determinado que a magnitude do valor é a magnitude da riqueza mercantil que foi produzida pelo trabalho social, pelo esforço produtivo da sociedade desviado de outros fins. Para maiores detalhes, Carcanholo, 2012. A Dialética da Mercadoria: guia de leitura., disponível em, http:// carcanholo.cjb.net.

${ }^{6}$ Segundo maior banco de fomento do mundo responsável por cerca de $20 \%$ em média de todo crédito do país, condutor oficial e fornecedor de crédito para as privatizações no Brasil. Para análise, pesquisar em BANCO MUNDIAL: Políticas Operacionais. Avaliação Ambiental. OP 4.01, Janeiro, $1999 . \quad$ Disponível http://wbln0018.worldbank.org/html/eswwebsite.nsf/potwe?Open View\&Start=1\&Count=500000\&Expand=1\#1.

7 O capital ganha, na sociedade global, a sua forma mais abstrata e fluída, ele se desterritorializa como superação as limitações ao seu crescimento, ver Fredric Jameson, a discussão sobre estágio ontológico de flutuação do capital em: A cultura do dinheiro: ensaios sobre a globalização, 2001.
\end{abstract}

